\title{
Significance of Asymptomatic Persistent Epstein-Barr Viral Load in Pediatric Renal Transplant Recipients: North American Pediatric Renal Trials and Collaborative Studies Report
}

\author{
Asha Moudgil ${ }^{1}$, Karen Martz ${ }^{2}$, Therese Moore ${ }^{3}$, William E. Harmon ${ }^{4}$ and Vikas R. Dharnidharka ${ }^{*}, 5$ \\ ${ }^{1}$ Children National Medical Center, Washington D.C., USA \\ ${ }^{2}$ Emmes Corporation, Rockville, MD, USA \\ ${ }^{3}$ Mayo clinic, Rochester, MN, USA \\ ${ }^{4}$ Boston Children hospital, Boston, MA, USA \\ ${ }^{5}$ Washington University School of Medicine and St. Louis Children's Hospital, St. Louis, MO, USA
}

\begin{abstract}
Background: Many pediatric transplant (TX) centers routinely monitor Epstein-Barr (EB) viral load (VL) by real time quantitative PCR and intervene to prevent post-transplant lymphoproliferative disorder (PTLD). Some children develop asymptomatic persistent VL (PVL). Outcome of different interventions in preventing PTLD and other undesired effects on acute rejection (AR), graft failure (GF) and function amongst children with asymptomatic PVL is not known.

Methods: NAPRTCS centers invited to enter data on children with asymptomatic PVL ( $\geq 6$ months) into the EB VL registry. Comparison group included children into the NAPRTCS TX arm during the same period without PVL or VL monitoring. EB VL were arbitrarily divided into low (1-10), medium (>10-100) and high $(>100$ times detection limit for the center) ratio.

Results: Of 645 children (18 centers), 85 (13.2\%) developed onset of PVL at a mean of $6.4 \pm 6.3$ months post-TX. PVL children were more likely to be younger $(<5$ years) at TX and less likely to be African-American and majority $(75.3 \%)$ was mismatched for EBV (donor EBV IgG positive and recipient negative). Thymoglobulin induction was used in $29.4 \%$ children with PVL versus $37 \%$ in controls ( $\mathrm{p}=\mathrm{ns})$. PTLD developed in 7/85 (8.2\%) children with PVL versus 5/560 $(0.9 \%)$ controls $(\mathrm{p}<0.0001)$. EB VL ratios were not different in those with and without PTLD. EB PVL as time varying covariate did not affect patient survival, GF and AR (HR, 0.85, 0.53 and 0.99). The change in GFR overtime in children with PVL was comparable to controls.
\end{abstract}

Conclusion: Children with PVL (actual load not predictive) are at increased risk for PTLD, but not for AR, death, GF or loss of graft function.

Keywords: Children, Epstein-Barr virus, kidney transplantation.

\section{BACKGROUND}

Post-transplant lymphoproliferative disorder (PTLD) is a serious complication in Epstein Barr virus (EBV) naïve children [1]. Most cases of PTLD are EBV driven and have evidence of EBV infection at diagnosis [2]. With the widespread availability of Epstein Barr (EB) viral load (VL) assays by real time quantitative polymerase chain reaction (RT-qPCR) for clinical purposes, many pediatric centers have adopted routine surveillance of their post-transplant patients for early detection of EB VL by RT-qPCR [3]. This strategy has led to detection of children with asymptomatic EB VL including a subset with persistent VL (PVL). Often, transplant nephrologists make immunosuppression (IS)

*Address correspondence to this author at the Division of Pediatric Nephrology, Washington University School of Medicine \& St. Louis Children's Hospital, Campus Box 8116, Room NWT 10-119, 660 South Euclid Avenue, St Louis, MO 63110, USA; Tel: 314-286-1574;

Fax: 314-286-2351; E-mail: Dharnidharka_V@kids.wustl.edu adjustments and add other therapies (antiviral medications, intravenous immunoglobulin, cytogam, and rituximab) to decrease EB VL in order to prevent PTLD. However, excessive reduction of IS may lead to acute rejection (AR)and graft dysfunction. Outcome of pediatric patients with asymptomatic EB PVL and these interventions is not well characterized. In pediatric heart transplant (TX) recipients, $45 \%$ children with PVL developed PTLD [4]. In contrast, the rate of progression to PTLD was less than $10 \%$ in pediatric liver transplant recipients [5]. In this study, we sought to ascertain the incidence of PVL and progression rate to PTLD in pediatric kidney transplant recipients, as well as the impact of different interventions on patient and graft survival and graft function. This data was collected from 18 pediatric transplant centers participating in the North American Pediatric Renal Trials and Collaborative Studies Report (NAPRTCS) registry. 


\section{METHODS}

NAPRTCS is a voluntary consortium of pediatric nephrology centers in the United States and Canada with the aim of standardized data collection on patients with chronic kidney disease, those receiving dialysis and after transplant to help provide pediatric specific benchmarking data to improve quality of care for these children. The data elements collected and methodology are described in the NAPRTCS annual report [6]. The data is entered on line in a password protected database. All participating centers (144) have approval of their respective institutional review boards to enter data into this registry.

\section{EB PVL Registry}

EB PVL registry was newly created for this study within the NAPRTCS, as data on EB VL was not originally collected in the NAPRTCS transplant arm. Each participating center routinely measuring post-transplant EB VL by RT-q PCR was asked to enter additional information on their patients with EB PVL into this registry and given a small reimbursement for each completed form. Patients meeting the following inclusion criteria were eligible for participation in the EB PVL registry: 1. Transplant after January $1,2005,2$. those with persistent ( $\geq 2$ positive VL or $\geq 2 / 3$ of measured VL positive over 6 months) EB VL, 3 . asymptomatic (no symptoms of EBV infection or PTLD prior to first VL detection and over 6 months afterwards during viral surveillance), 4 . follow-up of at least 1 year after fulfilling criteria for EB PVL. After data entry was completed, the first author sought clarifications from the participating centers through telephone interviews and email communications. Other patients enrolled into NAPRTCS transplant arm without PVL or VL monitoring from these 18 centers during the same time served as controls. Of note, some of these control patients may have had transient VL or progressed to PTLD within 6 months of EB VL detection.

\section{Data Collected}

Data on demographics, EBV and cytomegalovirus (CMV) serologies of the donor and recipient at transplant, induction therapies (monoclonal, polyclonal antibody thymoglobulin and no induction), maintenance immunosuppression, type of specimen for EB VL assay (whole blood, plasma, serum or lymphocytes), and VL detection limit of each laboratory was collected. The frequency of monitoring of EBV VL was 1-3 months and in case of more frequent monitoring in case of positive VL, centers were asked to enter only one (highest) value per month. In addition, type of intervention after detection of first EB VL (reduction in immunosuppression, antiviral medications, intravenous immunoglobulin and rituximab), information on PTLD, patient and graft survival, acute rejection and graft function was collected. Estimated Glomerular filtration rate (eGFR) was calculated by using modified old Schwartz formula described in the NAPRTCS annual report. As there were different assays used for measuring EB VL in different centers, EB VL ratio using the peak viral load value over 6 months period (measured VL in the specimen/VL detection limit for the laboratory) was calculated and arbitrarily divided into low (1-10), medium $(>10-100)$ and high $(>100)$. The incidence of PTLD was compared amongst children with different $\mathrm{VL}$ ratios to assess if incidence of PTLD increased with increasing VL.

\section{Statistics}

Demographics and categorical variables between EB PVL and controls were compared by chi-square analysis. Cox regression model with development of EB PVL used as time varying covariate adjusted for age, race and gender was used to compare patient survival, graft survival, time to acute rejection and to PTLD between those with EB PVL and controls. A repeated measures linear regression analysis also adjusted for age at transplant, race and gender was used to compare eGFR during follow-up between EB PVL and controls. $\mathrm{P}$ value of $<0.05$ was considered significant. All analyses were conducted using SAS version 9.2 (Cary, NC).

\section{RESULTS}

\section{Incidence of Asymptomatic EB PVL}

Eighteen pediatric transplant institutions participating in this study enrolled 645 children in the NAPRTCS transplant arm from January 2005-April 2011. Of these, 85 were reported to have EB PVL (Cumulative incidence 13.2\%, incidence at each center ranged range between $2.7-32 \%$ ). Onset of EB PVL was first detected at a mean \pm SD of $6.4 \pm$ 6.3 (median 4.2, range 0-35.5) months after transplant.

\section{Viral Load Assays}

Of 18 centers, 13 centers (68 children) had EB VL measurement in the whole blood (detection limits of 60-2000 copies $/ \mathrm{ml}), 4$ centers (10 children) in the plasma (detection limits of $120-250$ copies $/ \mathrm{ml}), 2$ centers (5 children) in the serum (detection limits of 100-2000 copies/ml), 1 center $(2$ children) in the lymphocytes (detection limit 150 copies $/ 10^{5}$ lymphocytes). Note that 2 centers had more than one type of measurement.

\section{Risk Factors for EB PVL}

Young ( $<5$ years of age) and Caucasian children were more likely to develop PVL. Thymoglobulin induction was not identified as a risk factor for PVL (Table 1). As data on the CMV and EBV serostatus was not available in the control group since these data are not routinely collected in the master transplant registry, CMV and EBV mismatched status could not be compared between children with PVL and controls. However, of children with EB PVL, 55/73 $(75.3 \%)$ were mismatched (Donor + and recipient - ) for EBV IgG and 37/80 (46.3\%) were mismatched for CMV IgG. The data were missing for the remaining children.

\section{Peak Viral Load Ratio Over 6 Months and Induction Therapy in EBV Mismatched Children}

Comparison of peak median VL ratio over 6 months in children receiving induction therapy with Thymoglobulin to those with anti-IL-2R antibodies in EBV mismatched 
Table 1. Risk factors for EB persistent viral load.

\begin{tabular}{|c|c|c|c|}
\hline Risk Factors & $\begin{array}{c}\text { PVL } \\
\text { N (\%) } \\
85(13.2)\end{array}$ & $\begin{array}{c}\text { Controls } \\
\mathrm{N}(\%) \\
\mathbf{5 6 0}(86.8)\end{array}$ & P-Value \\
\hline Age $<5$ years & $34(40.0)$ & $83(14.8)$ & $<0.0001$ \\
\hline Male & $44(51.8)$ & $328(58.6)$ & NS \\
\hline Caucasian & $53(62.4)$ & $295(52.7)$ & \multirow{2}{*}{0.025} \\
\hline A-A & $10(11.8)$ & $123(22.0)$ & \\
\hline Thymoglobulin & $25(29.4)$ & $207(37)$ & \multirow{4}{*}{ NS } \\
\hline Anti-IL-2 R & $31(36.4)$ & $170(30.4)$ & \\
\hline No induction & $27(31.7)$ & $132(23.6)$ & \\
\hline Other induction/Combination therapies & $2(2.4)$ & $51(9)$ & \\
\hline
\end{tabular}

children is shown in Table 2. Seven children receiving induction with other agents or no induction were excluded from this analysis. Though median VL ratio was higher in children who received induction therapy with Thymoglobulin compared to those with anti-IL-2R antibodies (1500 versus 92, $\mathrm{p}$ 0.044), the proportion of those with low, medium and high VL ratio was not different in the two groups $(\mathrm{p}=0.179)$.

Table 2. Peak EB VL over 6 months and induction therapy in EBV mismatched children.

\begin{tabular}{|c|c|c|}
\hline $\begin{array}{c}\text { Peak VL Ratio } \\
\text { Over 6 Months }\end{array}$ & $\begin{array}{c}\text { Thymoglobulin } \\
\text { N (\%) }\end{array}$ & $\begin{array}{c}\text { Anti-IL-2 R } \\
\text { N (\%) }\end{array}$ \\
\hline \hline N & 21 & 27 \\
\hline $\begin{array}{c}\text { Low } \\
1-10\end{array}$ & $2(9.5)$ & $2(7.4)$ \\
\hline $\begin{array}{c}\text { Medium } \\
>10-100\end{array}$ & $4(19.1)$ & $12(44.4)$ \\
\hline $\begin{array}{c}\text { High } \\
>100\end{array}$ & $15(71.4)$ & $13(48.2)$ \\
\hline Median VL & 1500 & 92 \\
\hline
\end{tabular}

Chi-square p-value $=0.179$

Median test $\mathrm{p}$-value $=0.044$

\section{Intervention in EB PVL Patients}

Of 85 children in the category of EB PVL, 45 (52.9\%) had reduction or discontinuation of IS. Of 45 children, 19 $(42.2 \%)$ had $20-66 \%$ reduction in the dose of Mycophenolate mofetil (MMF) or Azathioprine (AZA), whereas 26 (57.8\%) children discontinued MMF or AZA. The CNI dose was reduced by $9-71 \%$ in $52(62.2 \%)$ children and discontinued in 1 child. In $20(23.5 \%)$ children anti-viral medications were used; Valganciclovir was used for 1 month- $>3$ years in 17 children and Cytogam was used in 3 children. In 3 children, 2-4 doses of Rituximab were used.

\section{PTLD}

Of 645 children in the study, 12 developed PTLD with the overall incidence of $1.9 \%$. Seven of 85 (8.2\%) with PVL versus $5 / 560(0.9 \%)$ control children developed PTLD $(\mathrm{p}=0.0001)$. PTLD developed at a mean of $16.4 \pm 8.9$ (median 15, range 8-33) months after TX in the EB PVL group and at a mean of $7.5 \pm 1.7$ (median 8.4, range 5.4-8.8) months after TX in the control group. Amongst 85 children with PVL, 0/5 (0.0\%) with low, $3 / 30(10.0 \%)$ with medium and 4/50 (8\%) with high VL ratio developed PTLD (Table 3). Amongst children with PVL, 4/7 (57.1\%) with PTLD and 41 $178(52.6 \%)$ children without PTLD had reduction in IS $(\mathrm{p}=\mathrm{ns})$. Antiviral therapy was used in $1 / 7(14.2 \%)$ children with PTLD versus in 15/78 (19.2\%) without PTLD ( $p=n s)$.

Table 3. Peak EBV VL ratio in patients with and without PTLD in EBV PVL group.

\begin{tabular}{|c|c|c|}
\hline $\begin{array}{c}\text { Peak VL Ratio } \\
\text { Before PTLD* }\end{array}$ & $\begin{array}{c}\text { Non-PTLD } \\
\text { N (\%) }\end{array}$ & $\begin{array}{c}\text { PTLD } \\
\text { N (\%) }\end{array}$ \\
\hline \hline N & 78 & 7 \\
\hline $\begin{array}{c}\text { Low } \\
1-10\end{array}$ & $5(6.4)$ & $0(0.0)$ \\
\hline $\begin{array}{c}\text { Medium } \\
>10-100\end{array}$ & $27(34.6)$ & $3(42.9)$ \\
\hline $\begin{array}{c}\text { High } \\
>100\end{array}$ & $46(59.0)$ & $4(57.1)$ \\
\hline Median VL & 161 & 138 \\
\hline
\end{tabular}

*In patients not developing PTLD, the peak VL over the course of follow-up was used. Chi-square p-value $=0.750$. Median test $p$-value $=0.719$

\section{PTLD in PVL Group}

Of 7 children with PTLD, 5 developed PTLD within 1 year of fulfilling diagnostic criteria for PVL. Of these, 2 had received induction with thymoglobulin and 5 received with anti-IL-2R antibodies. Of these, 3 children had PTLD limited to tonsils and adenoids and were treated with further reduction in IS, 4 doses of rituximab and removal of tonsils and adenoids. Three children had PTLD limited to lymph nodes, 2 were treated with further reduction in IS, and 4 doses of Rituximab and one with decrease in IS alone. One child developed PTLD involving central nervous system and was treated with further reduction in IS, rituximab (16 doses), followed by chemotherapy. All children with PTLD were alive with functioning graft at last follow up.

\section{Effect of EB PVL on the Patient and Graft Survival, Acute Rejection and Graft Function}

EB PVL as time varying covariate adjusted for age, race and gender showed no impact on patient and graft survival or acute rejection (Table 4). However, it was strongly associated with risk of subsequent development of PTLD (Table 4 and Fig. 1). The slope of change in eGFR over time was not different in children with EB PVL and controls (Fig. 2).

\section{DISCUSSION}

Our data shows that routine monitoring of EB VL by RTqPCR identifies a group of children with asymptomatic PVL that is at risk for subsequent development of PTLD despite 
varying degree of empiric interventions. The incidence of PTLD amongst these children with PVL was $8.2 \%$, much higher than the overall incidence of $1.9 \%$ in this study and overall reported incidence of PTLD (mostly 1\%) amongst children after renal transplantation [7]. In this study young, Caucasian and EBV mismatched children were more likely and African-American children were less likely to develop PVL. These demographic and clinical characteristics have been identified as risk factors for PTLD in the previous studies; however, these characteristics have not been previously assessed for development of EB PVL [1, 8-10].

Table 4. Effect of EB PVL(Time Varying Covariate adjusted for Age, Race and Gender) on patient and graft survival, acute rejection and PTLD.

\begin{tabular}{|c|c|c|c|}
\hline Cox Regression & HR & $\mathbf{9 5 \%}$ CI & p-Value \\
\hline \hline Patient Survival & 0.85 & $0.10-7.61$ & 0.88 \\
\hline Graft Failure & 0.53 & $0.20-1.38$ & 0.19 \\
\hline Acute Rejection & 0.99 & $0.56-1.75$ & 0.98 \\
\hline PTLD & 11.05 & $3.30-37.05$ & $<0.0001$ \\
\hline
\end{tabular}

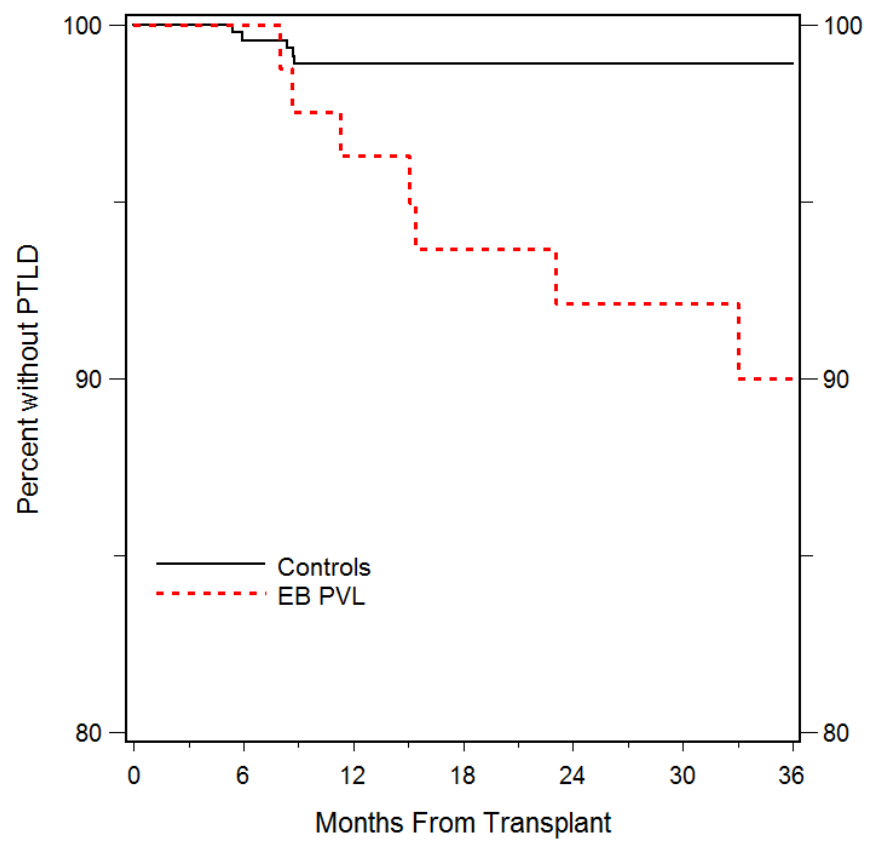

Fig. (1). Percent without PTLD in controls and those with EB PVL. Kaplan Meier graph showing percentage of children without PTLD overtime amongst children with EB PVL and controls. More children in PVL group developed PTLD overtime. All children with PTLD in the control group developed it in the first 9 months of transplantation.

Concern has been raised that thymoglobulin may play a role in the development of PTLD as it has been shown to deplete poly functional $\mathrm{T}$ cells in HIV infected kidney transplant recipients and activate EBV replication [11]. Even though the median VL was high in EBV mismatched children receiving induction with thymoglobulin, it was not identified as a risk factor for a higher proportion of children developing EB PVL in this study. Previous studies have provided mixed results regarding the role of polyclonal antibodies in increasing risk for PTLD [12], perhaps due to intermixing of ALG and equine ATG (Atgam) with rabbitATG (Thymogloubulin). When Thymoglobulin has been assessed separately from the other polyclonal antibodies, the risk for PTLD has not been elevated [13]. The role of Thymoglobulin in EB PVL has not been previously assessed. Though the NAPRTCS lumps all polyclonal antibodies into one group, our data pertains to Thymoglobulin as during the time period of this study, the only polyclonal antibody being used for induction is Thymoglobulin and the older agents ALG and Atgam are no longer being used for renal transplant recipients.

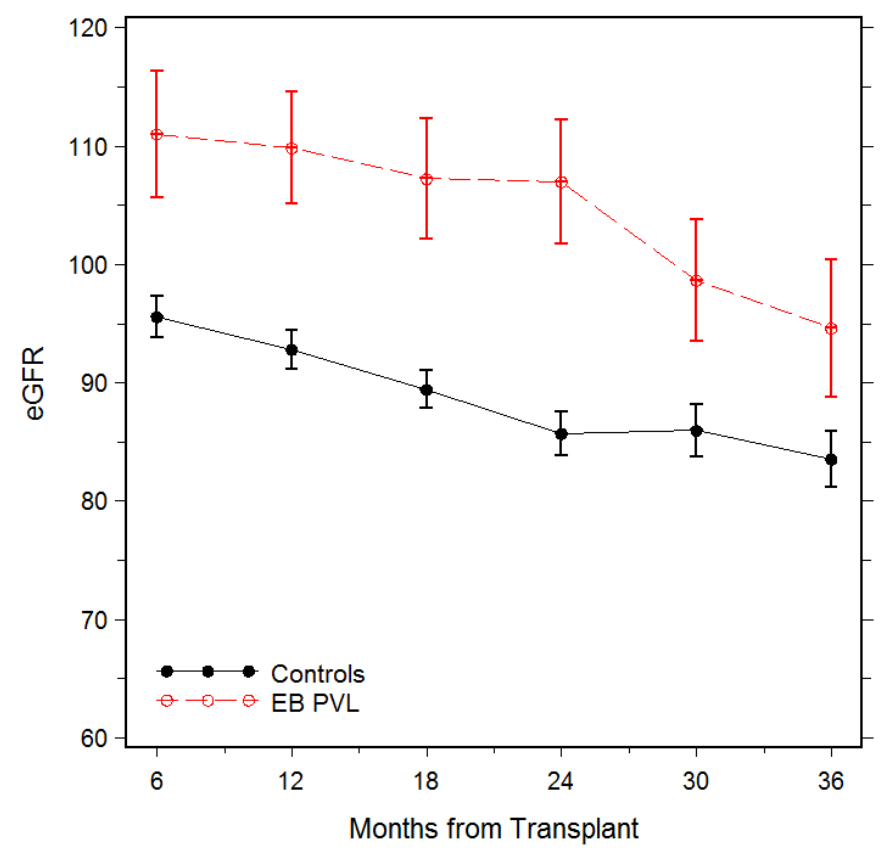

Fig. (2). Change in eGFR overtime in controls and those with EB PVL. Shows change in GFR overtime in children with EB PVL and controls. The slope of change in eGFR was not different.

In our control group, 5 children developed PTLD within the first 9 months post-TX (Fig. 1). Of these, 4 were not prospectively monitored and EB VL was not detected in one. However, all children had evidence of EBV infection on histologic examination. It is plausible that prospective monitoring in these children may have detected EB VL, as negative predictive value of $\mathrm{EB}$ VL for EBV infection is high [14]. However, it is unlikely that these children would have qualified for PVL since the time period between TX and PTLD was rather short ( $7.5 \pm 1.7$ months).

RT-qPCR to measure EB VL varies across different centers with 4 different type of specimens (whole blood, plasma, serum and lymphocytes) used with different laboratory cut-off values. We tried to tackle this problem by calculating VL ratio as intra-laboratory variation is small [15]. RT-qPCR is the most sensitive method available for viral quantitation $[16,17]$. The type of specimen needed for best clinical correlation with EB VL has not been settled. Since EBV causes proliferation of B-cells in the latent stage, cell based assays (whole blood and lymphocytes) provide estimation of B-cell proliferation induced by latent EBV, whereas plasma and serum assays reflect either EBV actively released from the B-cells in the replicating phase or passive release of latent EBV from breakdown of EBV infected B- 
cells. Though EB VL measurement in the whole blood was the most commonly used assay in this study (68 of 85 children), the actual peak VL was not helpful in predicting PTLD. A recent study by Hocker et al. did not find correlation between EB VL and duration of VL with PTLD or EBV associated diseases [18]. Thus, this study and that by Hocker et al. show that EB PVL alone has a low predictive value for PTLD. However, prospective EBV VL monitoring improves predictability of PTLD over no monitoring at all. It was also reassuring that none of the 5 children with low VL developed PTLD. Additional assays including measurement of EBV specific cytotoxic T-cells generation [19] or B-cell dysfunction [20] in addition to measurement of EB VL has been suggested to help refine prediction of PTLD. However, these assays need further validation for clinical purposes.

Reduction of IS has been the cornerstone of preventing PTLD [21]. However, there are no guidelines on how to reduce IS safely in children with EB PVL to prevent PTLD, while not increasing the risk for AR, graft loss or graft dysfunction. In this study, we could not show the difference in the incidence of PTLD amongst children with PVL who had decrease in IS versus those who did not. This may be related to the small number of PTLD cases. However, it was reassuring that decrease in IS did not lead to increased incidence of AR, graft loss and graft dysfunction suggestive of the fact that these children were likely to be over immunosuppressed. However, we did not assess the risk of developing de novo donor specific antibodies (DSA) after reduction in IS which may compromise graft function in the future. Antiviral medications have been suggested to decrease PTLD, but effect of antivirals could not be assessed due to small number of children receiving antivirals and low incidence of PTLD in this study [22].

Limitations of this study include retrospective registry data analysis, lack of uniform control arm (including both monitored and not monitored children and possibility of including some children with transient VL), and lack of standardization of EBV assays though we tried to address the later by calculating VL ratio.

In conclusion, EB PVL develops in a subset of children (most mismatched for EBV) after renal transplantation. Young, Caucasian and EBV mismatched children are at risk for PVL, whereas thymoglobulin induction does not confer increased risk. Children with moderate to high PVL (actual load not predictive) are at risk for PTLD despite empiric interventions but not at increased risk for AR, death, GF or loss of graft function. There is a need for standardization of EB VL assays and interventions including immunologic monitoring for DSA development to fully elucidate the role of EB PVL in pediatric renal transplant recipients. Additional assays of EBV specific T-cell cytotoxicity and or B-cell function are needed to help further define the risk of PTLD amongst children with EB PVL.

\section{AUTHOR'S CONTRIBUTIONS}

Asha Moudgil: Study design and manuscript writing.

Karen Martz: Statistical analysis.

Therese Moore: Data collection.

William E. Harmon: Manuscript writing and critique.
Vikas R. Dharnidharka: Study design and manuscript writing.

$$
\begin{aligned}
& \text { ABBREVIATIONS } \\
& \mathrm{AR}=\text { Acute rejection } \\
& \mathrm{AZA}=\text { Azathioprine } \\
& \mathrm{CMV} \quad=\text { Cytomegalovirus } \\
& \text { CNI }=\text { Calcineurin inhibitor } \\
& \text { EBV }=\text { Epstein Barr Virus } \\
& \text { eGFR = Estimated glomerular filtration rate } \\
& \text { IS } \quad=\text { Immunosuppression } \\
& \text { IVIG = Intravenous immunoglobulin } \\
& \text { MMF = Mycophenolate mofetil } \\
& \text { NAPRTCS }=\text { North American Pediatric Renal Trials and } \\
& \text { Collaborative Studies Report } \\
& \text { PTLD = Post-transplant lymphoproliferative disorder } \\
& \text { PVL }=\text { Persistent viral load } \\
& \text { RT-qPCR = Real time quantitative polymerase chain } \\
& \text { reaction } \\
& \text { VL } \quad=\text { Viral Load }
\end{aligned}
$$

\section{CONFLICT OF INTEREST}

The authors confirm that this article content has no conflict of interest.

\section{ACKNOWLEDGEMENTS}

Dr. Dharnidharka is supported in part by the Washington University Institute of Clinical and Translational Sciences grant UL1 TR000448 from the National Center for Advancing Translational Sciences (NCATS) of the National Institutes of Health (NIH).

This study was presented in part at American Transplant Congress 2012 and funded by an investigator initiated grant to VRD, AM and NAPRTCS by Genzyme Inc.

\section{Collaborators and Centers:}

- Amrish Jain, Children's Hospital of Michigan, Detroit, MI.

- $\quad$ Ann P. Guillot, University of Vermont, Burlington, VT.

- Asha Moudgil, Children National Medical Center, Washington, D.C.

- $\quad$ Bradley A. Warady, Children's Mercy Hospital, Kansas City, MO.

- Charles Davis, Cleveland Clinic Foundation, Cleveland, $\mathrm{OH}$.

- Dawn S. Milliner, Mayo clinic, Rochester, MN.

- Dechu Puliyanda, Cedars-Sinai Medical Center, LA, CA.

- Eileen Ellis, Arkansas Children's Hospital, Little Rock, AR. 
- $\quad$ Eunice G. John, University of Illinois, Chicago, IL. John Brandt, M.D, University of New Mexico School of Medicine, Albuquerque, NM.

- ManjulaGowrishankar, Stollery Children's Hospital/ University of Alberta Alberta, CN.

- Maria Ferris, University of North Carolina, Chapel Hill, NC.

- Mazen Y. Arar, University of Texas HSC, San Antonio, TX.

- S. Paul Hmiel, St. Louis Children's Hospital, St Louis, MO.

- Samhar I. Al-Akash Driscoll Children's Kidney Center, Corpus Christi, TX.

- Tom Blydt-Hansen, Children's Hospital of Winnipeg, Winnipeg, Manitoba, CN.

- Vikas R. Dharnidharka, University of Florida, Gainesville, FL.

- William Harmon, Boston Children Hospital, Boston, MA.

\section{REFERENCES}

[1] Dharnidharka VR, Sullivan EK, Stablein DM, Tejani AH, Harmon WE. Risk factors for posttransplant lymphoproliferative disorder (PTLD) in pediatric kidney transplantation: a report of the North American Pediatric Renal Transplant Cooperative Study (NAPRTCS). Transplantation 2001; 71(8): 1065-8.

[2] Paya CV, Fung JJ, Nalesnik MA, et al. Epstein-Barr virus-induced posttransplant lymphoproliferative disorders. ASTS/ASTP EBVPTLD Task Force and The Mayo Clinic Organized International Consensus Development Meeting. Transplantation 1999; 68(10): 1517-25.

[3] Merlino C, Cavallo R, Bergallo M, et al. Quantitative PCR in EBV-infected renal transplant patients. New Microbiol 2001; 24(3): 223-9.

[4] Bingler MA, Feingold B, Miller SA, et al. Chronic high EpsteinBarr viral load state and risk for late-onset posttransplant lymphoproliferative disease/lymphoma in children. Am J Transplant 2008; 8(2): 442-5.

[5] Green M, Soltys K, Rowe DT, Webber SA, Mazareigos G. Chronic high Epstein-Barr viral load carriage in pediatric liver transplant recipients. Pediatr Transplant 2009; 13(3): 319-23.

[6] NAPRTCS annual report. [cited 01-30-2013]; Available from: https://web.emmes.com/study/ped/annlrept/2010 Report.pdf

[7] Cleper R, Ben Shalom E, Landau D, et al. Post-transplantation lymphoproliferative disorder in pediatric kidney-transplant recipients - a national study. Pediatr Tranplant 2012; 16(6): 619-26.
[8] McDonald RA, Smith JM, Ho M, et al. Incidence of PTLD in pediatric renal transplant recipients receiving basiliximab, calcineurin inhibitor, sirolimus and steroids. Am J Transplant 2008; 8(5): 984-9.

[9] Quinlan SC, Pfeiffer RM, Morton LM, Engels EA. Risk factors for early-onset and late-onset post-transplant lymphoproliferative disorder in kidney recipients in the United States. Am J Hemtol 2011; 86(2): 206-9.

[10] Dharnidharka VR, Lamb KE, Gregg JA, Meier-Kriesche HU. Associations between EBV serostatus and organ transplant type in PTLD risk: an analysis of the SRTR National Registry Data in the United States. Am J Transplant 2012; 12(4): 976-83.

[11] Gasser O, Bihl F, Sanghavi S, et al. Treatment-dependent loss of polyfunctional $\mathrm{CD} 8+\mathrm{T}$-cell responses in $\mathrm{HIV}$-infected kidney transplant recipients is associated with herpes virus reactivation. Am J Transplant 2009; 9(4): 794-803.

[12] Kasiske BL, Kukla A, Thomas D, et al. Lymphoproliferative disorders after adult kidney transplant: epidemiology and comparison of registry report with claims-based diagnoses. Am J Kidney Dis 2011; 58(6): 971-80.

[13] Caillard S, Dharnidharka V, Agodoa L, Bohen E, Abbott K. Posttransplant lymphoproliferative disorders after renal transplantation in the United States in era of modern immunosuppression. Transplantation 2005; 80(9): 1233-43.

[14] Toyoda M, Moudgil A, Warady BA, Puliyanda DP, Jordan SC. Clinical significance of peripheral blood Epstein-Barr viral load monitoring using polymerase chain reaction in renal transplant recipients. Pediatr Tranplant 2008; 12(7): 778-84.

[15] Preiksaitis JK, Pang XL, Fox JD, Fenton JM, Caliendo AM, Miller GG. Interlaboratory comparison of epstein-barr virus viral load assays. Am J Transplant 2009; 9(2): 269-79.

[16] Watzinger F, Suda M, Preuner S, et al. Real-time quantitative PCR assays for detection and monitoring of pathogenic human viruses in immunosuppressed pediatric patients. J Clin Microbiol 2004; 42(11): 5189-98.

[17] Loginov R, Aalto S, Piiparinen $\mathrm{H}$, et al. Monitoring of EBVDNAemia by quantitative real-time PCR after adult liver transplantation. J Clin Virol 2006; 37(2): 104-8.

[18] Hocker B, Fickenscher H, Delecluse HJ, et al. Epidemiology and morbidity of epstein-barr virus infection in pediatric renal transplant recipients: a multicenter, prospective study. Clin infect Dis 2013; 56: 84-92

[19] Jinadu L GS, Pao A, Kamil E, Jordan SC, Puliyanda D, Toyoda M. Measurement of EBV specific cytotoxic T cells (EBV-Tc) in renal transplant patients 2009. Am J Transplant 2009; 715.

[20] Engels EA, Preiksaitis J, Zingone A, Landgren O. Circulating antibody free light chains and risk of posttransplant lymphoproliferative disorder. Am J Transplant 2012; 12(5): 1268-74.

[21] Gross TG. Chronic active Epstein-Barr virus--is it real and how do you treat it? Pediatric transplant 2009; 13(2): 146-7.

[22] Trappe R, Riess H, Anagnostopoulos I, et al. Efficiency of antiviral therapy plus IVIG in a case of primary EBV infection associated PTLD refractory to rituximab, chemotherapy, and antiviral therapy alone. Ann Hematol 2009; 88(2): 167-72. 